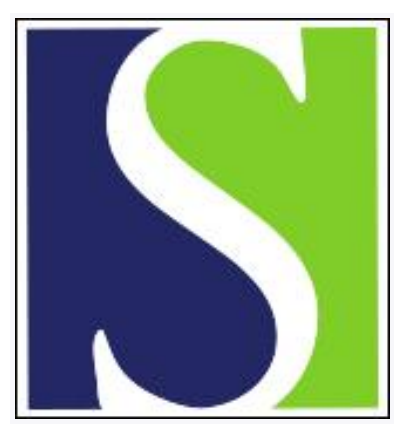

Scand J Work Environ Health 1988;14(5):273-279

https://doi.org/10.5271/sjweh.1920

Issue date: Oct 1988

Strategy for the primary and secondary prevention of occupational diseases in the German Democratic Republic.

by Bachmann W

Affiliation: Central Institute of Occupational Medicine, Berlin, German Democratic Republic.

This article in PubMed: www.ncbi.nlm.nih.gov/pubmed/3201185

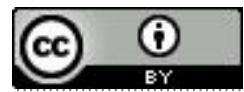




\title{
Strategy for the primary and secondary prevention of occupational diseases in the German Democratic Republic
}

\author{
by $\mathrm{W}$ Bachmann ${ }^{1}$
}

\begin{abstract}
BACHMANN W. Strategy for the primary and secondary prevention of occupational diseases in the German Democratic Republic. Scand J Work Environ Health 14 (1988) 273-279. This review explains the German Democratic Republic's strategy for preventing occupational diseases, which is considered one of the primary purposes of public health. It is a complex challenge that is being tackled through close cooperation between enterprise-linked occupational health services, the inspectorates of industrial hygiene, public health centers, and trade unions. In primary prevention, planning is based on results obtained in thorough analyses of all the relevant parameters, such as work conditions, industrial accidents, occupational diseases, morbidity records, and the quality of social services, and a complex work analysis has been developed to provide comprehensive and measurable information on health hazards due to harmful physical and chemical factors, dust, and job-related physical and neuropsychic stresses. Primary prevention is realized mainly through the elimination of health hazards and the improvement of work conditions, both based on a comprehensive framework of legislation. At the level of secondary prevention, company-linked occupational health services are a part of the national health service. Altogether, approximately $75 \%$ of the work force is covered by occupational health services. A nationwide information system consists of compatible components for primary and secondary prevention, thus enabling control of exposure-effect relationships and the optimization of health policy.
\end{abstract}

Key terms: accident, environmental factors, health services, hygienic guidelines, information system, methodology, professional disease.

\section{Primary prevention of occupational diseases}

The improvement of occupational health and individual efficiency are major components of economic and social policies pursued in the German Democratic Republic (GDR). All important aspects of occupational health, including responsibilities, demands, rights, and duties, are formally stated in legislation $(5,7,8,9,10$, 12,15 ).

The persistent containment of occupational diseases has been formulated as the prime purpose of public health (16). Hence particular attention is given to the most common and the severest occupational diseases. This is a complex challenge which is being tackled in close cooperation by enterprise-linked occupational health services, inspectorates of industrial hygiene, public health centers, and trade unions. Teamwork between all of them is ensured at all levels of management and is guided by the principle that any case of occupational disease should be a good reason for a critical appraisal of existing work conditions and for occupational health monitoring.

More effective advantage ought to be taken of all sorts of facilities for primary and secondary prevention, and new approaches should be devised for the high-continuity improvement of occupational health care.

\footnotetext{
1 Central Institute of Occupational Medicine, Berlin, German Democratic Republic.
}

Reprint requests to: Dr W Bachmann, Zentralinstitut für Arbeitsmedizin, Nöldnerstrasse 40-42, 1134 Berlin, DDR.
The annual rate of certified occupational diseases is showing a declining trend in all industries of the GDR because of the planned and concentrated technological, organizational, medical, and social measures being taken at the company level. By 1987, the incidence of occupational diseases had decreased by about $40 \%$ from the approximate 12300 cases registered in 1976. Severity, too, has been mitigated. The rate of notifiable industrial accidents decreased by about $25 \%$ in the same period. It should be emphasized in this context that overall labor productivity in the GDR national economy increased by roughly $60 \%$ from 1976 to 1987.

This positive balance is likely to demonstrate the great importance attributed to occupational health and the firm integration of occupational health with management at the ministerial, corporation, and company levels. For the elimination of unnecessary jobrelated difficulties and hazards to health, concrete and detailed measures are formally provided in company planning, above all scientific and technical measures and plan components for working and living conditions. Potentially concerned company departments, shopfloor sections, technologies, and workplaces are explicitly named in the plan components, together with the number of workers involved.

In our country, with its mix of industries, planning is based on results obtained in profound analyses of all relevant parameters, such as work conditions, industrial accidents, occupational diseases, morbidity records, and the quality of social services. Labor safety 
specialists, medical officers, and union representatives are involved in the planning discussions, and they take an active part in the drafting of priority tasks for forthcoming planning periods. The company manager is held fully responsible for providing adequate occupational health conditions in the company concerned. In this context, the manager must provide an account to the company work force and union bodies at regular intervals.

It is an established policy guideline that any measure of socialist intensification for higher productivity and company effectiveness must be combined with action to improve work conditions for the labor involved. However, technoscientific progress does not automatically produce health-adjusted and personality-building characteristics of work. The design of equipment and production sites and the planning of technologies require due consideration not only of technological and economic criteria, but of aspects related to occupational science, occupational medicine, and social conditions as well. It is as early as the preparatory phases for production that decisions are actually made concerning the nature and conditions of future work, that is, concerning the tasks, role, and position of the individual worker in the process of production in society. Belated modification of inadequately designed work conditions is usually not economical and thus is unsatisfactory.

Roughly 230000 workplaces are annually renewed or redesigned along with the modernization of shopfloor sections and complete plants and through the translation of findings obtained from scientifically substantiated work organization into practice. A general improvement in work conditions is the result. Health hazards and stress caused by hard physical work are completely eliminated for 25000 to 30000 workers every year.

Practice in the majority of enterprises has been characterized by the following situations: (i) occupational health is planned, implemented, and followed by company management in cooperation with the shopsteward's committee and other union bodies, (ii) priorities for modernizing production facilities and sanitation projects are formulated with due consideration of information obtained on occupational hygiene in the company concerned, (iii) conditions for self-control in terms of the occupational hygiene of job-related difficulties and health risks are established and expanded in terms of personnel and equipment, (iv) designers of machines, technological processes, and buildings have to produce evidence for thorough consideration in the design of occupational health requirements, (v) inventors and innovators are motivated to work on lessening health risks and easing work, and (vi) demands for order, safety, and discipline have been made challenge items of socialist competition programs for high-quality performance.

Skilled personnel are available in 15 inspectorates of industrial hygiene at the regional level and in 220 inspectorates at the district level to support company management and union officials in carrying out their responsibilities in occupational health (11). These inspectorates are flanked by 10 industry-related centers of industrial hygiene. The inspectorates and centers are controlled and guided by the GDR Ministry of Health, the Division of Company-Linked Occupational Health and the inspectorates of industrial hygiene. They are technically subordinate to the regional or district medical of ficers in charge of the area in which they are situated.

Approximately 2200 workers are employed in the inspectorates and centers and work under the guidance of specialists in occupational medicine. Included are physicians, engineers, physicists, chemists, psychologists, and other professionals for guidance, counseling, and follow-up in all fields of company-linked industrial hygiene.

Scientifically substantiated rules and regulations, codes of practice, and projects have proved to be of great importance to occupational health at the company level. They reflect the preventive orientation of GDR health policy. They serve as legal instruments to ensure that in all GDR industries machines, systems, technologies, and shopfloor structures are designed and completed with a view to avoiding or at least minimizing occupational health risks and unnecessary jobrelated difficulties $(8,9)$.

GDR standards (TGL) with exposure limits and measuring methods were introduced in 1969 for the purpose of adequate industrial hygiene (14). Such standards are issued by the National Agency for Standardisation, Measurement, and Product Testing, following consultation with government authorities under the GDR Ministry of Health. They are scientifically prepared and formulated at the GDR Central Institute of Occupational Medicine (ZAM) in cooperation with competent partners.

In the meantime, $110 \mathrm{GDR}$ standards on industrial hygiene have come into force. They concern noise, whole-body and local vibration, chemical agents (220 maximum acceptable concentrations), nontoxic fibrogenic and nonfibrogenic dusts, microclimate, lighting, electromagnetic fields, and the dimensioning of standing and seated workstations. Additional rules and regulations have been adopted and introduced regarding occupational activities of women and adolescents (6), together with specific recommendations for the evaluation and limitation of hard physical work with reference to age and sex $(1,2)$.

The industrial hygiene standards are used as criteria for the analysis, evaluation, and structuring of work. They are norms for the qualitative and quantitative characterization of major parameters of work conditions and tools for the purpose of optimizing occupational activities. They establish the properties and features by which tools, processes, organizational patterns, and environmental conditions are to be charac- 
terized for health-oriented, stimulating, and personality-developing occupational activity.

Enterprise management in the GDR is legally bound to compliance with the standards and exposure limits which have actually resulted from research in all fields of occupational medicine and consideration of international findings. Hence the regulations are all medically substantiated and formulated so that, with their observance and on the basis of an 8-h workday, occupational damage to health can be prevented throughout occupational life.

Compliance with the demands has often proved to be somewhat difficult for certain enterprises, primarily those of smaller size or with outdated technologies not yet modernized for economic reasons and a shortage of funds. Compromise solutions have to be implemented in such cases. Personal protective equipment has to be used to compensate for the lack of sufficient primary protection, and medical monitoring has to be intensified. Yet, even new machines and imported installations are sometimes found to fall short of the industrial hygiene criteria so that modification and resetting may be required.

Any management finding itself incapable of complying with the mandatory rules on industrial hygiene is legally bound to apply for a special permit (14) before it deviates from the regulations. Such situations may develop in cases in which valid exposure limits are greatly surpassed for temporarily inevitable reasons or many workers are affected or occupational diseases have already developed. Applications are to be submitted to the proper inspectorate of industrial hygiene at the regional level and must include shortterm, medium-term, and long-term programs for remedial action in the form of engineering, technology, organization, and medical care. The programs have to be presented by the company manager in person. A time-limited permit may be granted after scrutiny that is usually accompanied by on-the-spot inspection, and it is often hinged on conditions to be met by the recipient of the permit. Should an application be made against the background of a particularly critical situation, the National Expert Committee on Industrial Hygiene will intervene to pass on the application and complementary information and recommendations to the GDR Minister of Health for the final decision making.

Planned action on job layout for the primary prevention of occupational diseases depends on information about current conditions. One cannot simply rely on sporadic workplace analysis and accidental checking on whatever harmful factor. A system of methods for complex workplace analysis in the context of good industrial hygiene has, therefore, been devised in occupational medicine and has been thoroughly tested in all industries for several years. This complex workplace analysis was elevated to legal status in 1981 and is now binding for enterprise management and the inspectorates of industrial hygiene (3). It covers all job-related requirements, exposures, and stress factors. Management of all enterprises, according to the valid labor safety statutes (9), are obliged to present detailed reports annually on their health-risk workplaces with explicit reference to the noxious agents and stress factors implied.

The complex work analysis has been formulated to provide comprehensive and measurable information on health hazards due to harmful physical and chemical factors, industrial dust, and job-related physical and neuropsychic stresses. A full-scale methodology for analysis and evaluation has been worked out for each of the factors involved. Health risks and occupational stresses are rated against a general reference which is based on all the industrial hygiene regulations and mandatory exposure limits. The principle for this procedure may be seen from the following, highly simplified list:

$1.0=$ no exposure to noxious agents

$0.8=$ exposure always below the exposure limit

$0.6=$ performance and individual comfort affected by work conditions

$0.5=$ exposure identical to the exposure limit

$0.2=$ exposure drastically above the exposure limit

$0.0=$ exposure limit surpassed by several magnitudes

Such a graduated list has proved to be advantageous, as it has eliminated the need for dealing with a multitude of single pieces of information. The stress profile of a given workplace may be seen at first glance from its rating. Additional data on specific activities and on an enterprise as a whole are available in the form of computerized documentation. If the assumption is made that the mandatory regulations and exposure limits are of sufficient validity and reliability, these ratings may be assumed to characterize the probabilities of health damage.

The aforementioned compulsory enterprise reporting on industrial hygiene at workplaces is based on this methodology. Reports have to be submitted by the management of companies with ten workers or more. They are checked and supplemented for regional analysis by the proper inspectorate of industrial hygiene at the regional level and are forwarded to the GDR Central Institute of Occupational Medicine for computerized evaluation.

Comprehensive data on the industrial hygiene conditions of about 7.3 million workers have been stored in the industrial hygiene information system. The usefulness of the system in terms of health policy and practice has been clearly demonstrated from the very beginning, as it makes essential data continuously available to the Council of Ministers, specialized ministries, the National Executive of the Confederation of Free German Trade Unions, industrial unions, corporation and company management, and regional authorities for the following purposes: (i) the assessment of industrial hygiene by industries; (ii) the planning of priority action to alleviate health risks and other job-relat- 
ed problems; (iii) the verification of effectiveness of previous measures taken to improve work conditions; and (iv) the planning and enforcement of extended care in occupational medicine.

Analyses of industrial accidents and occupational diseases, together with analyses of the general situation in industrial hygiene, are annually on the agenda of joint discussions of the Council of Ministers with the National Executive of the Confederation of Free German Trade Unions. The conclusions resulting from such meetings are incorporated in planning at the industrial, corporation, and company levels.

The elimination of hazards and unnecessary difficulties from production processes and work conditions has continued to be the major approach to the prevention of occupational diseases. Effective contributions can be made to primary prevention by the national health service and health institutions in the form of scientifically substantiated indices and guidelines, practical methods for analysis, and realistic information on existing situations.

\section{Secondary prevention of occupational diseases}

Company-linked occupational health services in the GDR are part of the national health service. They are in charge of the medical care of workers in their occupational environment and have to ensure the secondary prevention of occupational diseases. Roughly 13000 medical of ficers and nurses are available in 137 company-linked outpatient clinics, 334 company-linked doctor-staffed medical units, 1953 doctor-staffed company-linked medical outposts, and 1330 outposts staffed with nurses. Sixty-five percent of the work force in the GDR is under the direct care of company-linked occupational health services. This total, for all practical purposes, is further increased to $75 \%$ when the services rendered by occupational health personnel affiliated with other institutions of public health are included. A very high degree of occupational health services is available close to the workplaces in areas of high industrial concentration.

Medical officers at the workplace level in the GDR carry out their duties under the assumption that prevention, diagnosis, therapy, and after care form one unity (4). They are independent of company management in terms of career promotion and finance and, therefore, can live up to their responsibilities without constraint. Company-linked occupational health services are technically subordinate to the district medical officer but are under the professional guidance and control of the inspectorate of industrial hygiene in charge of their area.

Medical officers at the workplace level can be specialists in general practice, internal medicine, dermatology, orthopedics, ophthalmology, gynecology, otorhinolaryngology, dentistry, and occupational medicine. These medical of ficers have a wide-ranging scope of responsibilities in the secondary prevention of occupational diseases, including first aid to casualties of industrial accidents, outpatient treatment of workers and their families, periodic examinations and screening, extended medical supervision of selected groups of workers, participation in the job assignment of convalescents under rehabilitation schemes, shopfloor visits to inspect work conditions, and the counseling of management on all issues of occupational health. General hygiene in factory canteens, common rooms, and sanitary installations, as well as health education of management and labor, are additional responsibilities. The ratio of preventive to curative services is 30 to 70 on the average. Medical officers at the workplace level are strongly involved in primary medical care but are usually in a better position to offer their skilled services on account of their thorough knowledge of patients' jobs and work conditions and permanent contact with the patients' occupational environment.

The first contact between a medical officer at the workplace level and a worker is made during the preemployment examination, before an employment contract is signed. Such a medical check-up may lead to therapeutic measures or after care. Other legal duties of the medical officer include regular fitness and monitoring checks of workers with particular occupational exposures to noxious agents and stress; occupational guidance for adolescents; specific health care for women, shift workers, and elderly employees; rehabilitation; and advice on the allocation of protected jobs to workers with occupational health problems.

Fitness screening and monitoring checks of workers potentially exposed to occupational health risks are among the most substantial methods used by the national health service in the early detection of occupational effects on human health, the prevention of occupational diseases, and the reduction of industrial accident rates and invalidity. They constitute a highly complex model of extended occupational health care.

A program of methods (13) came into force in 1981 to ensure health-adjusted employment even at workplaces with inevitable health risks and other job-related difficulties. The program provides for the compulsory medical examination of defined groups of workers prior to employment or at regular intervals or before transfer to another job within the same enterprise. Occupational fitness and monitoring checks are compulsory for the following categories of workers: (i) adolescents up to their 18th birthday; (ii) people with hard physical work; (iii) workers exposed to harmful physical factors, chemical agents, and dusts; (iv) workers exposed to sources of infection; (v) workers involved in high-risk activities, such as night shifts, work at visual display units, work with risk of falling, the handling of explosives, work on high-voltage installations, work with respirators, and the operation of conveying and hoisting equipment; and (vi) workers with so- 
cial considerations, including women with several children and individuals close to retirement. Provisions of the following nature apply to each group of workers under compulsory health monitoring: (i) informative definition of workplaces, typical activities, requirements, stress factors, potential hazards, and other jobrelated difficulties; (ii) detailed specification of methods to be used in the medical examinations; (iii) medical check-up intervals; and (iv) definition of functional disorders and diseases imposing limitations on or ruling out a certain activity under work conditions currently prevalent in the enterprise concerned.

In any medical check-up for occupational fitness assessment, the medical officer must refer to all documentation available from complex industrial hygiene analyses of the workplace in question. A medical examination becomes compulsory as soon as a workplace rating is 0.5 or lower $(0.2,0.0)$. Management is not only obliged to document workplace ratings but also to give a verbal description of the peculiarities of exposures in agreement with preset classifications. Rating 0.5 , for example, stands for noise levels between 85 and $90 \mathrm{~dB}$ (A). Code number 76.1 must be added to describe "constant noise" or 76.2 for "variable noise without pulsed components," and 76.3 for "impulse noise". An alphabetic and systematic list has been issued on harmful chemical substances and dusts from which irritative, allergenic, fibrogenic, hematotoxic, hepatotoxic, neurotoxic, and carcinogenic qualities of substances can be derived.

Medical officers at the workplace level are furnished in the GDR with comprehensive information on exposures and other stress profiles and are thus in a good position to make an informed assessment of all aspects relevant to specific work conditions and the individual health of the worker, as well as to undertake a profound diagnosis of fitness for a concrete job and, if necessary, initiate adequate medical action. Medical decision making on occupational fitness, consequently, is based on parameters of individual disposition and concrete workplace-related exposures. Emphasis must be placed on determining whether an existing congenital or chronic disease may be adversely affected by harmful occupational factors and stresses and may thus cause deterioration of the individual's health condition.

In the past, medical action had to be taken without such basic information on stress-related diagnosis, therapy, and after care. The company-linked occupational health services have been elevated to higher quality standards owing to this highly differentiated program of methods for fitness and monitoring examinations in occupational medicine. Highly accurate information on health risks and job-related difficulties is of particular interest to the general practitioner or medical specialist involved in occupational health but not personally affiliated with a specific enterprise and thus not in regular contact with his or her patients' real work conditions.
Both management and the worker concerned will be informed about diagnostic findings by the medical officer. This practice ensures job assignment according to health. Limited fitness has been recorded over an extended period of time for 6 to $8 \%$ of all workers. In such cases, current jobs may be continued if provided with additional protection at the organizational, social, and medical levels. Preventive changes at a workplace may be recommended under certain circumstances. Unfitness has been recorded for 0.8 to $1.6 \%$ of the workers. Such medical findings will necessarily entail a change of job. The workers concerned have to be given health-adjusted jobs within their present enterprise, however, without any social disadvantage.

Roughly 1.2 million workers are annually involved in fitness and montoring checks by company-linked occupational health services. About $20 \%$ of these checks are made by medical specialists affiliated with institutions outside occupational health. Large-scale introduction of the program of fitness and monitoring examinations has clearly shown, on the other hand, that many medical decisions are still taken on the basis of expert opinion, say, individual discretion. Hence fitness criteria need further improvement. Too much room is still left for individualistic judgement. More basic knowledge has to be accumulated on the multifactorial etiology of numerous diseases and on the role played by individual disposition in the pathogenesis of occupational health disorders. Fitness criteria have so far rarely been subjects of research efforts in occupational medicine. It is, nevertheless, estimated that even with the instruments currently available the early detection of occupational effects on health is possible, and an effective contribution can be made to the prevention of occupational diseases. The assumption can be made that, in the long run, for workers with medically certified unfitness or limited fitness the probability for developing an occupational disease would have been much greater without the early detection of such occupational effects on health.

Important results obtained from medical examinations, just as the data recorded in complex workplace analyses, are entered into computer-adjusted files. Combined statistical evaluations of the workplace and health data have opened up unprecedented sources of epidemiologic information with great relevance to health policy orientation and research. The data compiled from fitness and monitoring checks in occupational medicine have provided the basis for the information system, which has been developed for occupational medicine since 1982.

Available from the developed information system are data on the incidence of findings and diagnoses subdivided by categories of activities, and these data can be processed to generate information by age, sex, industry, and company. An account is given in table 1 of findings by main groups of diagnosis (according to the International Classification of Diseases) for 
Table 1. Annual incidence of diseases diagnosed in health examinations according to diagnostic group and sex.

\begin{tabular}{|c|c|c|c|}
\hline \multirow[b]{2}{*}{ Diagnostic group ${ }^{a}$} & \multicolumn{3}{|c|}{ Annual incidence $(\%)$} \\
\hline & $\begin{array}{c}\text { Men } \\
(N=758595)\end{array}$ & $\begin{array}{c}\text { Women } \\
(\mathrm{N}=309204)\end{array}$ & $\begin{array}{c}\text { Total } \\
(\mathrm{N}=1067779)\end{array}$ \\
\hline Nervous system $(290-359)$ & 2.5 & 3.1 & 2.6 \\
\hline Visual organs $(360-379)$ & 8.7 & 7.1 & 8.2 \\
\hline Hearing organs $(380-389)$ & 4.6 & 1.6 & 3.7 \\
\hline Cardiovascular system (390-495) & 13.7 & 18.1 & 15.0 \\
\hline Respiratory system $(460-519)$ & 3.9 & 2.9 & 3.6 \\
\hline Digestive system $(520-579)$ & 5.4 & 4.1 & 5.0 \\
\hline Musculoskeletal system (710-739) & 21.2 & 19.4 & 20.7 \\
\hline Dermatoses $(680-709)$ & 2.8 & 2.7 & 2.8 \\
\hline Gynecological disorders $(610-640)$ & 0 & 0.7 & 0.2 \\
\hline Urogenital system $(580-599)$ & 0.8 & 1.6 & 1.0 \\
\hline
\end{tabular}

a Code of the International Classification of Diseases in parentheses.

Table 2. Relevance of selected findings for certain bodily systems to the fitness of a group of construction equipment operators.

\begin{tabular}{lcc}
\hline System & $\begin{array}{c}\text { Findings } \\
(\%)\end{array}$ & $\begin{array}{c}\text { Retevance } \\
\text { to fitness }(\%)\end{array}$ \\
\hline Nervous system & 1.5 & 36.4 \\
Visual organs & 5.7 & 21.4 \\
Respiratory system & 3.6 & 1.9 \\
Musculoskeletal system & 14.0 & 10.6 \\
Metabolic system & 2.1 & 13.3 \\
\hline
\end{tabular}

workers who have undergone occupational health checks in our country. The rates of incidence represent findings typical of GDR morbidity. It is, however, permissible to draw some conclusions as to the general health situation, since all the workers included are employed full-time. For example, the figures can be assumed to represent the percentage contributions of fitness-limiting findings to main groups of diagnosis, with particular reference to activities and their associated exposures and other stress conditions. The relevance of selected findings to fitness is given for a small group of construction equipment operators in table 2.

Data filed in the information system developed for occupational medicine may provide information on a wide range of important aspects, including the effectiveness of action taken for the primary prevention of occupational diseases, the quality of preventive occupational health checks, the general validity of industrial hygiene standards and exposure limits, and the effects of work conditions on general morbidity. Insights into such relations and implications are likely to strengthen the scientific basis for the exploration and implementation of more efficient forms of primary and secondary prevention.

\section{Information system in occupational medicine}

The structures and prerequisites in GDR society have enabled centralized planning and control at the company, regional, industrial, and national levels for action to enhance work conditions and to reduce job- related difficulties and health risks. A specific information system was devised for this purpose in the GDR more than a decade ago. It has been tested and introduced into practice. It has made possible the identification of priority problems against the background of national health policy and national economy, and it facilitates both decision making at various levels and the assessment of efficiency. The information system is based on systematic periodic analyses of the following issues: (i) the industrial hygiene situation across the national economy, (ii) the incidence of occupational diseases, and (iii) the results recorded from fitness and monitoring examinations in occupational medicine. Each of these three items has been structured as a computer-supported system. System quality has been achieved through the implementation of compatibility of all the codes used and the many different possibilities of coupling the stored data.

\section{Industrial hygiene situation}

A methodology has been developed at the GDR Central Institute of Occupational Medicine for complex industrial hygiene analyses and assessment criteria. It has been introduced in all industries and is used by enterprises to report annually on health hazards due to potentially harmful factors and stresses. Reporting is compulsory, as mentioned earlier, for enterprises employing 10 workers or more. Detailed information has thus become available on the types and dimensions of job-related difficulties and health hazards for the workplaces of about 8.3 million people.

\section{Occupational diseases}

The incidence of of ficially recognized and registered occupational diseases has been annually evaluated for the entire GDR for a number of years. Reported suspicion, harmful factors, length of exposure, activity, age, sex, type of occupational disease, severity of physical damage, measures initiated for sanitation and rehabilitation, and the name of the enterprise, industry, region, etc, are among the data recorded for statistical and epidemiologic analysis. 


\section{Preventive examinations}

The new program of methods for fitness and monitoring examinations in occupational medicine has been extremely helpful in expanding possibilities for the adequate assessment of the general health situation of the working population. Information not accessible in the past on general and activity-related morbidity has now become available from the combined statistical evaluation of workplace data and health data. The processing of data recorded from about 1.2 periodic checks at regular intervals during the year provides information on the incidence of findings and diagnoses and their relevance to occupational fitness by groups of activity, age, and sex for enterprises, industries, and regions. Resulting medical action, at the same time, becomes overseeable under the presented aspects of evaluation, for example, the prescription of sheltered jobs, the continuation of treatment, extended medical care or change of workplace. Ninety relevant diagnoses are now open to activity-related evaluation, according to the international classification of diseases of the nervous, cardiovascular, respiratory, digestive, and musculoskeletal systems, sensory organs, skin, and some additional categories.

The information system in occupational medicine has become an instrument of substantive importance to management, planning, and follow-up for the GDR Council of Ministers, the National Executive of the Confederation of Free German Trade Unions, and all affiliated industrial unions, ministries, corporations, enterprises, and local authorities. Information has proved to be obtainable from the system in the following contexts: (i) effectiveness of measures taken to improve work conditions; (ii) unresolved problems and thus priorities in industrial hygiene that ought to be tackled in the sanitation and modernization program; (iii) types, magnitudes, and distribution patterns of job-related health disorders, in the context of real incidence; (iv) activity-related, age-related, and sexrelated general morbidity; (v) current position in occupational medicine and necessary input; (vi) validity and dependability of industrial hygiene standards and exposure limits; and (vii) health-related components of the labor potential in society.

\section{References}

1. Frauendorf H, Kobryn U. Richtlinie für die Analyse und Bewertung ausgewählter Formen körperlicher Arbeit. Z Gesamte Hyg 21 (1985) 21-23.

2. Frauendorf H, Kobryn U. Physiologische Parameter zur Beurteilung der physischen Dauerleistungsfähigkeit bei dynamischer Arbeit mit unterschiedlichen Muskelmassen. Z Gesamte Hyg 28 (1982) 438-441.

3. Klatt R, Schindler W, Konetzke G, ed. Der Betriebsarzt. VEB Verlag Volk und Gesundheit, Berlin 1985.

4. GDR Ministry of Health, ed. Arbeitshygienische Komplexanalyse. Staatsverlag der DDR, Berlin 1982, pp $8-90$.

5. —. Verfassung der DDR. Staatsverlag der DDR, Berlin 1968, p 18. (Kapitel 10).

6. - Arbeitsschutzanordung 5 - Arbeitsschutz für Frauen und Jugendliche. Gesetzblatt der DDR I (1973): 44,465 .

7. Gesetz über die örtlichen Volksvertretungen und ihrer Organe in der DDR. Gesetzblatt der DDR I (1973): $32,313$.

8. Arbeitsgesetzbuch. Staatsverlag der DDR, Berlin 1977, pp 201-222. (Kapitel 10).

9. - Arbeitsschutzverordnung. Gesetzblatt der DDR I (1977): 36, 405.

10. _ - Verordnung über das Betriebsgesundheitswesen und die Arbeitshygieneinspektion. Gesetzblatt der DDR I (1978) 4, 61 .

11. _- Zweite Durchfuhrungsbestimmung zur Verordnung über das Betriebsgesundheitswesen und die Arbeitshygieneinspektion - Aufgaben und Struktur der Arbeitshygieneinspektion. Gesetzblatt der DDR I (1978): 4,67 .

12. $\quad$ Verordnung über die Verhütung, Meldung und Begutachtung von Berufskrankheiten. Gestzblatt der DDR I (1981): 12, 137.

13. Zweite Durchfuhrungbestimmung zur Verordnung über die Verhütung, Meldung und Begutachtung von Berufskrankheiten - Arbeitsmedizinische Tauglichkeits- und Überwachungsuntersuchungen. Gesetzblatt der DDR I (1981): 28, 337.

14. - . Arbeitshygienische Normen und MAK-Werte. Sixth edition. Verlag Tribüne, Berlin 1984.

15. Verordnung über die Standardisierung. Gesetzblatt der DDR I (1984): 12, 157.

16. - Direktive des XI: Parteitages der SED zum Funfjahrplan fur die Entwicklung der Volkswirtschaft in der DDR in den Jahren 1986-1990. Dietz Verlag, Berlin 1986.

Received for publication: 17 June 1988 